\title{
TEORÍA DE LA LIBERTAD DE ELECCIÓN: APLICACIÓN EN LA PRAXIS ÉTICA
}

\author{
THEORY OF FREEDOM OF CHOICE: PRAXIS APPLICATION IN ETHICS \\ Ruth Mirihan Romero Huamani* \\ Docente Auxiliar de la Facultad de Ciencias Contables \\ Universidad Nacional Mayor de San Marcos-UNMSM / Lima-Perú \\ [Recepción: Setiembre de 2014/ Conformidad: Octubre 2014]
}

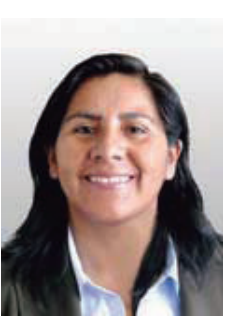

\section{RESUMEN}

El presente artículo tiene por objetivo analizar la Teoría de la libertad de elección y su aplicación en los actos humanos. Tesis que se aborda desde la ética aristotélica, conocido como teoría de la felicidad. Se revisa argumentos con mayor exegesis de la obra emblemática del filósofo Ética Nicomaquea (EN) apoyándose de otras obras. La finalidad es comprender la proaíresis como base del deseo, siendo esta la que determina cualquier acción humana bajo el pensamiento en vista del fin, que en la práctica subjetiva es requisito para cualquier acto deliberado, porque obedece a una serie de concausas del propio deseo. De esta teoría depende la comprensión de la libertad y su implicancia en otros aspectos como libertad de conciencia, pensamiento y entre otros. La metodología que se aplica es hermenéutica, y se encuentra dentro del enfoque cualitativo. Esto consiste en interpretar y dialogar con el autor, con la finalidad de contextualizar los aportes en los actos humanos.

Palabras clave:

Libertad de elección; ética del deseo; deliberación.

\begin{abstract}
This article aims at analyzing the theory of choice and its application to human actions. Thesis is approached from Aristotelian ethics, known as theory of happiness. Arguments more exegesis of the iconic work of the philosopher Nicomachean Ethics (EN) by relying from other works are reviewed. The purpose is to understand the proairesis the basis of desire, being the determining any human action under the thought in view of the end, which in practice subjective is required for any intentional, because due to a number of contributory causes of desire itself. This theory depends an understanding of freedom and its implication on other aspects such as freedom of conscience, thought and others. The methodology applied is hermeneutics, and is within the qualitative approach. This is to interpret and discuss with the author, in order to contextualize the contributions in human acts.
\end{abstract}

\section{Keywords:}

Freedom of choice; ethics of desire; deliberation.

* Maestra en filosofía. Universidad Iberoamericana de México, D. F. Email: romeroh24 @yahoo.es 


\section{INTRODUCCIÓN}

Se opta revisar y comprender desde la perspectiva ética y hermenéutica un tema específico en Aristóteles $^{1}$ : la libertad de elección. Encontramos en sus obras: la Ética Nicomáquea (EN), la Ética a Eudemo (EE), y en otros, análisis muy valiosos sobre los problemas de la elección. Es importante revisar teorías que ha surgido de la cuna de la cultura occidental y su vigencia en la comunidad científica, ya que la libertad como principio trascendental de la racionalidad es tan determinante en nuestras acciones que depende de nuestros deseos en cada decisión cotidiana. En la sociedad actual se habla de una seria de libertades, tales como: libertad de conciencia, pensamiento, expresión, elección, ideas, acción; pero se olvida su esencia; es por ello, hemos dedicado a contextualizar lo que el filósofo nos heredó en sus escritos. Razón que nos lleva aclarar, de la mano de Aristóteles, la responsabilidad del ser humano sobre sus actos.

La libertad de elección es algo que supone los actos de la deliberación y la decisión, lo cual permite que el ser humano pueda tener la libertad para elegir y llegar a la felicidad. La teoría de la libertad de elección se fundamenta en la toma de decisiones correctas o incorrectas; es decir, como seres humanos tenemos la obligación de entrenarnos en el camino correcto y escoger el camino del bien y la rectitud. También, tenemos la obligación de no sólo pensar en nosotros mismos y, en nuestro bienestar personal, cuando elegimos el camino de nuestras vidas, sino que, debemos preocuparnos por lo que nuestros pueblos o sociedades necesitan para llegar a su cometido. La praxis ética del hombre gira entorno a la búsqueda de la causa final que da sentido al bien humano, esto es a la felicidad. El sentido del artículo se mueve en tres puntos centrales: Bases causales de la teoría de la libertad, Teoría de la libertad de elección en esencia, Causas conjuntas de la deliberación, y finamente, las conclusiones y recomendaciones.

\section{BASES CAUSALES DE LA TEORÍA DE LA LIBERTAD}

En la sociedad actual se sigue dialogando sobre el concepto de la libertad como principio fundamental de la ética. Así como de la libertad de conciencia, pensamiento, expresión, elección, ideas, acción y, entre otros modos de comprender y aplicar en la vida cotidiana. Sin embargo, especialistas en diferentes ramas de la ciencia percibe a la libertad desde la perspectiva de la corriente utilitarista y gestalista o determinismo moderado, esto parece ser por la ausencia de la actualización de las bases teóricas de dicho principio, así como también, los principios de amor, justicia, igualdad, fraternidad. Por ello, la reflexión se centra en comprender la esencia de dichos principios y libertades que han sido desarrollados con mayor exégesis en el siglo III a. C., por Aristóteles. Los escritos acerca del tema siguen vigentes y necesarios en nuestra vida.

La base primaria de la libertad se encuentra en las cuatro causas fundamentales que justifican la esencia filosófica de Aristóteles, estas son: material, formal, eficiente $y$ final. En este punto se desarrolla de manera especial la causa eficiente de la acción que por ser una causa de posibilidades conlleva a comprender la libertad de elección como fuente esencial para hacer actividades en la vida humana. El agente o causa eficiente de la acción, lo señala Aristóteles en la Ética a Nicomaco (EN) que se ocupa de la causa eficiente de la acción; en el mismo pasaje en que se refiere a la causa final, el problema es: ¿Cuál es el principio del movimiento práctico en situaciones específicas del ser humano? La respuesta a esta pregunta se explica en este cuestionamiento: ¿ cuál es el lugar de la causa final en la génesis de la acción humana? Esto permitirá definir la naturaleza del movimiento práctico, tanto del anterior como del posterior. Según Aristóteles, "la causa de la acción (causa eficiente, no final) es la elección y la causa de la elección es el deseo y el pensamiento en vista del fin" (Aristóteles, EN VI 2, 1139a 31-34).

\footnotetext{
1 Aristóteles (en griego antiguo Apı Grecia cuyas ideas han ejercido una enorme influencia sobre la cultura intelectual de Occidente hasta la actualidad. Sus ideas vigentes aun en la cultura epistemológica y política humana.
}

170/ QVIPURAMAYOC|Vol. 22(42) 2014 
Esta tesis, del estagirita, trata de lo que causa inmediatamente a la acción, es la elección y lo que causa inmediatamente la elección es el deseo del fin y el pensamiento en vista del fin; es decir, la deliberación sobre los medios para alcanzar en situaciones específicas y circunstancias particulares. No hay, acción sin elección, ni elección sin deliberación, la cual tiene como causas tanto al deseo como al pensamiento en vista del fin y a la acción premeditada en busca del deseo. Ello implica que, la determinación de la práxis exige la determinación de la elección (proaíresis), que no puede darse sin la determinación previa de la voluntad (boúleusis); esta a su vez, exige la determinación de sus causas conjuntas, a saber: del deseo (órexis) y del pensamiento en vista del fin (lógos ho héneká tinos). Por otra parte, es imposible determinar estas causas sin la presencia del fin inmanente de la acción. En último término, hablamos del fin último del ser humano. Esta serie de nexos causales muestra que nos encontramos en el centro, no sólo de la filosofía aristotélica de la acción, sino también, de la filosofía aristotélica de los asuntos humanos que actualmente trasciende en la conciencia racional.

\section{TEORÍA DE LA LIBERTAD DE ELECCIÓN}

En la forma que trata Aristóteles el tema de la libertad de elección ${ }^{2}$ en la Ética A Nicómaco (EN), Ética a Eudemo (EE), Metafísica, Tratado del Alma y Movimiento de los animales ${ }^{3}$, según las diferentes interpretaciones que hace sobre el problema ontológico de la elección en el marco de las virtudes intelectuales tratadas en la EN, podemos ver una tensión entre considerar la elección (proaíresis) como inteligencia apetitiva (óretikos nous), o como apetito intelectual (órexis dianoetike). Es decir, "el principio de la acción, habla de la causa eficiente, de que procede el movimiento, no del final que es la elección; y el de la elección que es el apetito y el raciocinio en vista de un fin. Por esto, es por lo que no puede haber elección sin entendimiento $y$ pensamiento". (VI 2, 1139a: 32 -35).

Para analizar la cuestión de la elección (proaíresis) Aristóteles (III 2, 1112a: 15-17) plantea una serie de interrogantes:
¿Que será, pues, la elección, o cuál su naturaleza, ya que no es ninguna de las cosas dichas? Cosa voluntaria ya se ve que es, por más que no todo lo voluntario sea elegible. ¿No será, entonces, lo que ha sido objeto de una deliberación previa? La elección, en efecto va acompañada de razón y comparación reflexiva (pensamiento y razonamiento): y la palabra misma parece sugerir que la elección es tal porque en ella escogemos una cosa de preferencia a otras.

La dificultad del asunto como puede vislumbrarse es la posición dualista en que el autor de la EN unas veces se inclina hacia una postura intelectualista de la libertad, y otras hacia una postura voluntarista.

En su cuestionamiento sobre la elección el Estagirita es consciente de que el ser humano puede tomar una decisión entre dos cosas distintas. En la EN no se conforma con explicar la responsabilidad del individuo sobre sus actos, lo que supone que el ser humano es la causa motriz de sus acciones, sino que divide los actos del ser humano en voluntarios y no voluntarios con lo cual encara de manera más nítida la relación entre la libertad y la necesidad.

La libertad y la necesidad la encontramos en Aristóteles, cuyo tema ha sido analizado muy bien, es crítico según el filosofo Acevedo, J. (2008); ya que, en Aristóteles hay una distinción entre actos que están orientados a un fin; sobre todo la idea del bien, influenciado por Sócrates y Platón: "Todo arte y toda investigación científica (cualquier doctrina), lo mismo que toda acción y elección, parecen tender a algún bien. Por ello, definieron con toda pulcritud el bien del que dijeron ser aquello a lo que todas las cosas aspiran". (I 1, 1094a: 1-3); y a los actos arbitrarios que no parecen tener una finalidad clara, ya que son más "espontáneos", o bien que son el fruto de ciertas circunstancias.

Aristóteles hace una muy importante distinción entre los actos que son voluntarios, en un sentido genérico, y los actos voluntarios en un sentido específico o activo que son realmente querer algo. Voluntario puede significar que alguien tuvo la capacidad de llevar a cabo cierta acción, pero voluntario puede ser

2 Sobre la proaíresis véase EN III 4 y EE II 3, 1105 a 26 ss. Su definición viene dada en la EN VI 2, 1139 b 5-6 y III 5, 1113a 11-12. 3 Hace referencia a tres obras esenciales de tal teoría. EN VI 2, 1139 b 5; EE VIII 2, 1246b 36; y Met. I 2, 982b 26. También, sobre el papel de la voluntad en la decisión cfr. EN VI 2, 1139b 5. 
algo más, es realmente querer llevar a cabo tal acto. Para que ocurra este segundo, se necesita que intervenga la reflexión, pues alguien por ignorancia puede no conocer las consecuencias de ciertas acciones, y no podría decirse que realmente quería aquello, aunque su acto sí puede decirse que fue voluntario en el sentido genérico. También, podríamos pensar en alguien que queriendo cierto fin específico, al llevar su propósito a la acción pudieran hacer intervenir factores que interrumpiesen o cambiasen e incluso llegasen a desvirtuar el fin perseguido, no pudiéndose decir tampoco de estas acciones que fueron realmente queridas o deseadas. Veamos lo que dice el filósofo. (III I, 1110 a 13-20):

... el que obra lo hace voluntariamente, puesto que, en tales acciones el principio del movimiento de sus miembros -que son como instrumentos de la voluntad- en él reside, y todo aquello cuyo principio está en él, también estará en él hacerlo o no hacerlo. Por consiguiente tales actos son voluntarios, por más que, absolutamente hablando, podrían decirse involuntarios, pues nadie escogería hacer ninguno de ellos en sí mismo considerado.

Tenemos entonces que, según el autor, el ser humano se pone en acción por sus propios deseos, esto es, en el sentido activo del para qué se elige hacer algo. Hay muchos motivos que se buscan como fin de una acción: lo honesto, lo útil, lo placentero, etcétera. Pero, algunos eligen algo pensando por ejemplo que ciertas cosas son honestas o útiles yluego, resulta que en realidad no lo son, es decir, existe la posibilidad de errar en la elección. Sin embargo, para Aristóteles, como el hombre prudente o sabio siempre reflexiona antes de actuar, en él sí es posible encontrar que su elección es casi siempre acertada. Hemos dicho que existen una gran variedad de motivos o fines de la acción, pero para el estagirita hay en el fondo un fin al cual todos tendemos irremediablemente y al cual se hallan sujetos, en cierto modo, los demás fines: la felicidad (eudaimonía) (I 4, 1095a :18-22).

En cuanto al nombre por lo menos, reina acuerdo casi unánime, pues tanto la mayoría como los espíritus selectos llaman a ese bien la felicidad, y suponen que es lo mismo vivir bien obrar bien que ser feliz. La esencia de la felicidad es cuestión disputada, y no la explican del mismo modo el vulgo y los doctos.

Aunque existen como se ha mencionaado una diversidad de fines, Aristóteles pregunta por un fin que sea deseable por sí mismo y no por sus efectos, un fin que guarde una relación intrínseca con la naturaleza del ser humano; hay fines particulares cuya consecución produce satisfacciones de deseos particulares, pero si todos los seres humanos en el fondo poseen la misma esencia, bien pudiera ser que hubiera lo más deseable para el ser humano como tal, y esto lo liga Aristóteles con la razón divina, causa final del Universo. Veamos la afirmación de Acevedo (Op.ct.):

El nous theos es el ser que en verdad podemos llamar feliz, debido a que se complace en la contemplación de sí mismo, y está libre de cualquier tipo de deseos externos, pues su fin es él mismo. En cambio la felicidad de los hombres es mudable, pues si consiste en la riqueza tan pronto como se pierde ésta recae en la infelicidad. No es el placer ni la riqueza el sumo bien y la felicidad, sino la actividad contemplativa o teórica, en la cual se ejercita la cualidad distintiva de la especie humana: la razón. Al hacer uso de la razón y llevar cabo la vida contemplativa (biós theoretikos) el ser humano realiza lo divino que hay en él, y en ese sentido iguala a la divinidad, aunque por supuesto, no de manera absoluta.

La felicidad para las personas son vivencias momentáneas, pero para Aristóteles es la búsqueda permanente y una vida en su plenitud.

\section{La elección en el sentido objetivo y subjetivo}

La "elección se puede entender en el sentido objetivo a lo que es preferido por alguien, como cuando se dice: ¿conoces cuál es mi elección?, o en el subjetivo de preferencia. Antes de Aristóteles predominaba el sentido objetivo de este término, aunque también se daba en lo subjetivo. Así algunos concebían la elección como un simple deseo, concupiscible o irascible, es decir, como un fenómeno puramente afectivo o emotivo, y otros lo consideraban como una especie de opinión. Aristóteles refuta los dos puntos de vista" 
(Cfr. EN III 2, 1111b 11-12; III 2, 1111b 12. \& III 3, 1111b 13-20, 20-30 y 31 ss) y describe la elección, como un fenómeno simultáneamente emotivo y cognitivo. Es lo que hace explícitamente en el siguiente texto: "la elección abarca, pues, necesariamente, tanto el intelecto o pensamiento como cierta disposición de carácter". Esto significa lo inseparable que es "un pensamiento que desea" como "un deseo que piensa" (VI $2,1139 \mathrm{~b} 4-5)$. Un pensamiento que se nutre del deseo $y$ orienta la tendencia que le es propia, y un deseo que despierta el pensamiento y se somete a sus directrices. O como Aristóteles en EN (III 3, 1113a 11-12. La misma idea se repite en el libro VI 2, 1139a 23. Y en VI 5, 1140a 32) dice en otros pasajes: "la elección, es un deseo deliberado de las cosas que están en nuestro poder". Argumentos que permiten comprender mejor la teoría de la libertad con esta tesis: "la causa de la elección es el deseo y el pensamiento en vista del fin". En realidad, el efecto inmediato de esta doble fuerza combinada, es la deliberación, que es, por su lado, la causa inmediata de la elección, como trataremos de ver en los siguientes párrafos de la elección práctica.

\section{El carácter práctico y subjetivo de la decisión deliberada}

En el contexto del carácter práctico de la acción, desde el plano subjetivo, vemos el predominio de la voluntad en el sentido práctico, que es la decisión. El carácter práctico tiende a las cuestiones morales que se encuentran en la realidad del ser humano, que fundamentalmente es una de las formas en donde la elección va a desarrollarse en el ámbito de la posibilidad. $Y$ la decisión en cuanto a la determinación se refiere más bien al acto de la voluntad ya que se relaciona a la operación misma, por la cual tendemos a decidir. Por el carácter subjetivo, la dimensión práctica de la decisión corre paralela a su dimensión subjetiva. Sobre ello, Aristóteles hace extensas observaciones; la decisión no versa, se dice, sobre temas generales sino de lo particular tácticamente posible.
Este objeto esencial de la decisión, -lo que yo puedo hacer-tiene un marcado acento subjetivo, porque lo posible en el terreno de las acciones humanos no es simplemente como en el campo especulativo, algo posible en absoluto, -aquello que no encierra contradicción- sino como algo posible relativo, precisamente con relación al ser humano sustancial es donde se presenta la acción como quien debe decidir, "decido lo que yo puedo hacer ... la elección, en una palabra, se ejerce sobre lo que depende de nosotros". (III 2, 1111b 29).

Por ejemplo, nadie puede decidir si lloverá o no, cuando alguien puede pensar mucho de cómo cambiaría su decisión según fuera el caso, si lloviera o no; es más, la cuestión principal en torno a la cual gira una buena parte de las decisiones, es, precisamente el discernimiento acerca de si un determinado camino de acción estará o no dentro de las decisiones activas; pero, no se tomará nunca la decisión de llevar a cabo algo para lo cual, en el momento mismo de tomarla, se siente incapaz de realizar.

Sin embargo, es verdad, que para conocer el alcance de las capacidades de la acción, es necesario ejecutar la misma acción. En muchos casos se puede incluso aspirar a realizar algo más de lo que se pensaba sería capaz, y puede llegar a realizarse, por eso se ve que en una acción verdaderamente válida se necesita cierta audacia (Cfr. Llano. (1983:28-55).

También, se puede ver en la dimensión subjetiva las decisiones trasladadas a la cuestión de la posibilidad y de una acción hacia el campo ambiguo, esto sería todo aquello que es posible como: que se es capaz de hacer o decidir como ser humano ante los objetivos propuestos. Finalmente, esta dimensión toma en cuenta aquello que se ve limitada por la posibilidad de cada individuo: "querer es poder" ya que no todo está en nuestras manos, porque hay cosas que no se pueden realizar, pero ello no impide querer a sabiendas de aquello que no se puede hacer.

4 Lo que Aristóteles dice de la elección lo repite acerca de la acción excelente (eupraxía). Esta proposición ilustra, de paso, la teoría aristotélica según la cual la causa eficiente (en este caso, la elección, causa eficiente de la acción) se reduce a la causa final (causa final de la acción es la eupraxía) (1139a 34. VI 2 1139a 34-35).

5 Esto mismo afirma Aristóteles en relación con el movimiento local: "hay dos principios del movimiento local: el deseo y el intelecto" Acerca del alma III 10, 433a 9. Y un poco más adelante: "Estas dos facultades son, pues, principios del movimiento local: el intelecto y el deseo, entendiendo el intelecto que razona en vista de un fin, es decir, el intelecto práctico" (Ibíd., 1, 13-14). ¿Debe entenderse que toda acción implica algún tipo de movimiento local? Parece, en todo caso, que ésta debe entenderse según el modelo del movimiento local. 
Debemos atender que nuestras decisiones recaen no sobre las cosas o sobre los bienes, o sobre realidades exclusivamente objetivas, sino sobre los propios actos. De manera que cualquier decisión que tome recae sobre sí mismo. En otras palabras en la decisión yo me vinculo a mí misma, en tanto que en la opinión me desligo de dicho acto (cuando el asunto sobre el que opino no hace referencia expresa a mí misma) en este pasaje se puede verse claramente la diferencia entre decidir sobre y decidirse a.... Como señala, Choza, (1978: 201) "a nadie le pasa algo o nada por opinar, pero si por eligir" ". En algunos pasajes Aristóteles dice que las decisiones surgen no sólo para las deliberaciones intelectuales, sino también para la toma de postura del yo que decide, es decir, del ser humano mismo.

Cabe señalar que, la decisión no sólo es personal en su punto de partida, pues brota en cierta manera del propio ser humano; sino que es a la par personal en su punto de llegada, puesto que la decisión, surgida del ser humano, configura, a su vez, a este mismo ser humano: dice Aristóteles (Met. I 2, 982b 26), "por elegir lo bueno y lo malo nos hacemos nuestro carácter, pero no por opinar". Con razón podrá decir en su "Metafísica" que "la libertad no es otra cosa que ser causa de sí mismo", afirmación que debe hacerse en un sentido diverso, ya que parece hablar de lo mismo, por sus decisiones se hace causa de sí mismo, porque mediante ellas, se crea a sí mismo una segunda naturaleza, ensanchando o restringiendo las posibilidades de la que tiene el ser humano, con nuestras decisiones podemos acrecentar nuestro ser, o agrandar su vacío. Para Aristóteles las elecciones son objetos de alabanza por recaer sobre lo que debe hacerse, por ser teóricamente correctas, en tanto que la opinión lo es por ser verdadera, porque no afecta en la decisión. La elección tiene que ver con los medios, señala el estagirita, es decir, como un proceso del deseo que tiende a mirar hacia el fin, por tanto, la elección ejerce sobre lo que depende de nosotros, dicho de otro modo, es la voluntad la que hace que el ser humano sea causa de sí mismo. Como resumen de esta parte veamos el siguiente texto (EN III 3, $1112 \mathrm{~b}$

32; 1113a 1-10):

Resulta, pues, de todo lo dicho que el hombre es el principio de sus actos; que la deliberación recae sobre las cosas que pueden hacerse por él, y que los actos, a su vez se ejecutan para alcanzar otras cosas. El fin, además, no es deliberables, sino los medios. Por otra parte, tampoco se delibera sobre los datos concretos que son del dominio de la sensación (...) El objeto de la deliberación y el de la elección es el mismo, salvo que el de la elección es algo ya determinado, puesto que lo juzgado por la deliberación es lo que se elige. Todo el que indaga cómo ha de obrar, cesa en esta operación cuando refiere a sí mismo el principio de la acción, y más concretamente a la parte gobernativa del alma, que es la que elige (...) Así pues, siendo lo elegible algo que, estando en nuestra mano, apetecemos después de haber deliberado, la elección podría ser el apetito deliberado de las cosas que dependen de nosotros, toda vez que por el juicio que formamos después de haber deliberado, apetecemos algo conforme a la deliberación.

\section{CAUSAS CONJUNTAS DE LA DELIBERACIÓN}

Para comprender la deliberación, causa inmediata de la elección, es indispensable analizar sus causas conjuntas esto es a saber: el deseo y el pensamiento en vista del fin que determina nuestras acciones en la vida cotidiana. En: EN (VI 2, 1139a 32-1139b 7):

El principio de la acción -hablo de la causa eficiente, de que procede el movimiento, no del final- es la elección; y el de la elección es el apetito y el raciocinio en vista de un fin. Por esto es por lo que no puede haber elección sin entendimiento y pensamiento, como tampoco sin un hábito moral. La práctica del bien, no menos que de su contrario, no se dan en la esfera práctica sin pensamiento y sin carácter.

6 Que para su opinión “Aristóteles establece la elección como articulación entre entendimiento y voluntad en situación de equilibrio inestable, que corresponda a su propia duda acerca de si, se trata de una actividad volitiva o intelectual...", sin duda, así ocurre en Aristóteles, aunque históricamente la interpretación ha variado. 
El pensamiento, por sí mismo, nada mueve, sino sólo el pensamiento dirigido a un fin y que es práctico. Éste es también el principio del pensamiento productivo, porque todo el que hace algo lo hace en vista de algún fin, por más que el producto mismo no sea un fin absoluto, sino sólo un fin en una relación particular y de una operación particular. El acto moral, en cambio, es un fin en sí mismo, porque la buena acción es un fin, y a este fin tiende el apetito. Así pues, la elección es inteligencia apetitiva o apetito intelectual, $y$ un principio semejante es el hombre.

Sólo el ser humano es el que delibera sus actos, y es la causa de sus actos por la razón de dicha deliberación sobre los medios que hay que poner para alcanzar el fin. Se analizará ahora con más detalle la con-causalidad de la elección en el plano del deseo. El deseo es la virtud más importante del hombre. Es la búsqueda permanente de algo cercano o lejano. El placer. Es el proyecto más necesario que viene de la carencia de una necesidad, de equilibrio o completura.

\section{La causalidad del deseo}

Cuando se trata de comprender lo que causa al deseo, es necesario ver lo que antecede al movimiento práctico. Veamos los tipos de deseo que considera Aristóteles:

1. El nombre genérico del deseo es "órexis". Al género así llamado pertenecen tres especies de deseo: epithymía o apetito, que tiene por objeto los placeres del cuerpo ${ }^{7}$; thymós o deseo irascible ${ }^{8}$, que genera los sentimientos vinculados con la ambición y se centra en el honor y la gloria; y boúlêsis o deseo racional, que tiene como objeto propio el fin último del ser humano, se conciba éste como se conciba ${ }^{9}$. Causa conjunta de la deliberación es el deseo en cualquiera de sus tres especies, como se desprende de Ética a
Nicomaco (VII 5, 1149a 29-35), donde se habla de la pasión, y en donde interviene el apetito.

Por esta razón, solo el deseo racional puede ser causa de la deliberación porque se desemboca en una elección moralmente significativa, llamada a ser, según el Estagirita, una elección a la vez virtuosa y verdadera de la persona. Sin embargo, el deseo racional en las causas conjuntas del alma, y con ella su naturaleza, es vaga en algunas obras del autor.

El alma racional parece depender de lo irracional porque lo ubica en la parte irracional que corresponde al impulso (thymós), el querer (boúlêsis) y el apetito (epithymía) ${ }^{10}$. Esto tres modos esenciales del actuar formarían parte de las emociones que siempre serán controladas y sometidas por la racionalidad para el filósofo. Por esta razón, el deseo es movido por el intelecto deliberativo, que es objeto deseado Tratándose del deseo racional, éste sólo es movido por el fin de todos los fines, por el fin último del ser humano que, por serlo, es, al mismo tiempo el bien supremo. Como dijimos Aristóteles lo identifica con la felicidad (eudaimonía), la cual, según él, es el único objeto adecuado al deseo racional (Cfr. I VI, 1097a 25 - b 21).

2. En relación con la deliberación, la elección y la acción, el autor pone de relieve la función causal del deseo y; además, su carácter proposicional. Por ser el deseo lo que es, la elección misma es un deseo deliberado y por tanto inseparable del pensamiento, y con ello Aristóteles se mantendrá a igual distancia delos fenómenos puramente cognitivos o puramente emotivos, extremos en los que salían caer algunas posturas de las escuelas socráticas menores.

La función causal del deseo se pone de manifiesto en el contraste que Aristóteles establece entre él y la elección a la que conduce: mientras que el deseo gira en torno al fin, próximo o último, la elección es el medio para alcanzarlo. (III2, $1111 \mathrm{~b} 27$ y Cfr. $1112 \mathrm{~b}$ 34,1113a15, 1113b2.). Mientras que el deseo gira

7 Que epithymía es una especie de deseo (órexis) se dice explícitamente en (EN I 13, 1102b 30): la sede de los apetitos y del deseo en general ...

8 Es un término difícil de traducir y algunos lo han vertido por "cólera", otros por "brío" y otros por "auto-respeto", etc.

9 El ser humano posee una cualidad de movimiento, una característica innata y trascendental. Acerca del alma II 3, 414b 2: menciona juntas las tres especies de órexis.

10 En un texto emblemático acerca de la Política. (VII 15, 1334b 25), señala Aristóteles que: "existen en los niños tan pronto como han nacido, mientras que es propio de la razón y la inteligencia aparecen en ella sólo cuando se hacen mayores". 
preferentemente en torno al fin, la elección gira más bien en torno a los medios.

Como señalamos la elección (proaíresis) tiene como objeto "las cosas que están en nuestro poder" (III 2, 1111b 19-30.), y lo que inmediatamente está en nuestro poder no es el fin, sino los medios. A esto se llama el justo medio. El fin último del ser humano, como ya se ha dicho, Aristóteles lo identifica con la felicidad y constituye el érgon del ser humano, es decir la tarea que le corresponde es el de ser racional. Se halla, por tanto, inscrito en nuestra propia naturaleza. Esta doctrina de elección implica que el deseo sólo es movido por el fin: sea por el fin último, en el caso del deseo racional; o, sea por un fin intermedio y subordinado, en el caso de los deseos concupiscible e irascible. Una vez movido por el primero es deseado, es decir por la felicidad, que, por ser causa final mueve sin ser movida, por tanto, el deseo racional mueve todo lo demás en el dominio de la acción, y éste mueve en calidad de causa eficiente. En el Movimiento de los Animales, el estagirita, (700b 36 - 701a 1, y Cfr. Acerca del alma III 9-10; III 10, 433a 18-433b 1) es explícito respecto a éste: "el primer motor mueve sin ser movido, pero el deseo y la facultad desiderativa mueven siendo movidos". Esta concepción causal del deseo está en perfecto acuerdo, no sólo con la concepción aristotélica de la felicidad, sino también con su proposición psicológica según la cual es evidente que el deseo es la capacidad del alma que causa movimiento. Veamos lo que dice acerca de la facultad motora:

Con razón, por consiguiente, aparecen como causantes del movimiento los dos, el deseo y el pensamiento práctico: efectivamente, el objeto deseable mueve y también mueve el pensamiento precisamente porque su principio es el objeto deseable. Y, del mismo, la imaginación cuando mueve, no mueve sin deseo.

El principio motor, es por tanto, único: el objeto deseable. Y es que si los principios que mueven son dos, intelecto y deseo, será que mueven en virtud de una forma común. Ahora bien, la observación muestra que el intelecto no mueve sin deseo: la volición es, desde luego, un tipo de deseo y cuando uno se mueve en virtud del razonamiento es que se mueve en virtud de una volición. El deseo, por su parte, puede mover contraviniendo al razonamiento ya que el apetito es también un tipo de deseo. Por lo demás el intelecto acierta siempre, mientras que el deseo y la imaginación pueden acertar o no acertar. Por consiguiente, lo que causa el movimiento es siempre el objeto deseable que, a su vez, es lo bueno o lo que se presenta como bueno. Pero no cualquier objeto bueno, sino el bien realizable a través de la acción. Y el bien realizable a través de la acción es el que puede ser de otra manera que como es. Es, pues, evidente que la potencia motriz del alma es lo que se llama deseo.

La causa conjunta del deseo y del intelecto práctico respecto del movimiento local y de la elección no es, pues, estrictamente tal: aunque la causalidad del segundo es necesaria, no llega a constituirse como tal, sino después que la del primero se ha ejercido sobre él, podemos decir que la facultad originariamente motora, tanto respecto del movimiento local, en general, como de la elección, en particular, es la facultad del deseo. Pero no es, respecto de ellos, un motor inmóvil, sino un motor previamente movido por el fin, que es, en todos los casos, lo deseado.

Ahora bien, el deseo, particularmente el deseo racional, no es un motor completamente ciego, sino, por el contrario, un motor que goza de un cierto carácter proposicional. Aristóteles lo compara con la afirmación: "la prosecución y la evitación en la esfera del deseo corresponden a la afirmación y la negación en la esfera del intelecto"11. La tesis central es que el deseo se da cuando persigue su objeto y niega cuando huye de él. Por eso el deseo racional hace lo uno y lo otro en conformidad con la razón, es decir, con el intelecto deliberativo: que por una parte, lo mueve a buscar los medios para alcanzar lo deseado, y por otro, cuando este descubre lo adecuado, lo acepta y da lugar a la elección, que es un deseo deliberado en su máxima. 


\section{CONCLUSIONES}

1. La teoría permite ver que desde el punto de vista ético, se impone la virtud moral como una disposición de la mente con respecto a la elección y la elección como deseo deliberado, se sigue para que sea elección virtuosa. El pensamiento debe ser verdadero y el deseo correcto, y que el deseo persiga las mismas cosas que el pensamiento. La correspondencia entre la afirmación del pensamiento práctico y la prosecución del deseo, en la que se revela la actitud proposicional, da lugar a una especial clase de verdad propia del intelecto práctico: la verdad práctica.

2. Esta especie de pensamiento y de verdad es de carácter práctico, porque así como en el pensamiento teorético, que no es práctico ni productivo, su estado bueno o malo son la verdad y la falsedad, respectivamente, siendo la función puramente intelectual, sino, el buen estado de la parte que es práctica e intelectual consiste en la verdad concordante con la recta tendencia.

3. La analogía de la Ética a Nicómaco se repite en Acerca del alma en donde el autor constata que "cuando lo percibido es placentero o doloroso, la facultad sensitiva -como si de este modo estuviera afirmándolo o negándolo- lo persigue o se aleja de ello". La actitud proposicional que, según él, caracteriza a la actividad del deseo se desprende, además, de la doctrina del razonamiento práctico, por tanto, la vida cotidiana son las consecuencias de cada acción, producto de la elección, siendo parte la estructura lógica de la deliberación.

\section{REFERENCIAS BIBLIOGRÁFICAS}

1. ARISTÓTELES. (1954). Ética Nicomáquea. [Trad. Gómez Robledo, A.] UNAM. México.

2. ARISTÓTELES. (1999) Ética a Nicómaco, [Edición y Traducción: María Araujo y Julián Marías]. Centro de Estudios Políticos Constitucionales. Madrid.

3. ARISTÓTELES. Ética a Eudemo(1994), [Trad. Gómez Robledo, A.].UNAM. México.

4. ARISTÓteles. (2000). Política, UNAM, [Trad. Gómez Robledo, A.]. UNAM. México.

5. ARISTÓTELES. (2003). Acerca del Alma [Trad. Calvo Martínez, T.].Gredos. Madrid.

6. ACEVEDO, J. (2008). Un análisis sobre la problemática de la libertad en la filosofía griega antigua: de los presocráticos a Aristóteles. En: http://www.tuobra.unam.mx/publicadas/050127030745.html.

7. AUBENQUE, P.(1999). La Prudencia en Aristóteles.Cátedra. Barcelona.

8. BRAVO, F. (2000) Naturaleza de la acción. Revista Humanitas, Episteme NS, Vol. 20, No 2. Venezuela.

9. CHOZA, J. (2008). Conciencia y afectividad. Eunsa. Pamplona.

10. GÓMEZ A. (2009). Ensayo sobre las virtudes intelectuales. FCE. México.

11. LLANO, C. (2002). Las formas actuales de la libertad. Trillas. México.

12. LLANO, C. (1998). La idea práctica en la acción práctica. Trillas. México.

13. ROSS, D. (1972). Fundamentos de la Ética. Eudeba. Buenos Aires.

14. VV. AA. (2013). Ensayos Aristotélicos. UPM: Publicaciones Cruz O., S. A. México.

15. ZAGAL, H., y AGUILAR, S. (1996). Límites de la argumentación ética en Aristóteles: Logos, physis y éthos. Publicaciones Cruz O., S. A. México. 